\title{
Factors Associated with Pregnancy Outcomes in Hypertensive Pregnant Women in a District Hospital in Benin
}

\author{
Saizonou Jacques ${ }^{1 *}$, Glele-Ahanhanzo Yolaine ${ }^{2}$, Kpozehouen Alphonse ${ }^{2}$, \\ Tawo Mondoukpè̀ ${ }^{1}$ Ouendo Edgard-Marius ${ }^{1}$ \\ ${ }^{1}$ Department of Policies and Health Systems, Public Health Regional Institute, Ouidah, Benin \\ ${ }^{2}$ Department of Epidemiology and Biostatistics, Public Health Regional Institute, Ouidah, Benin \\ Email: *saizonoujacques@yahoo.fr
}

How to cite this paper: Jacques, S., Yolaine, G.-A., Alphonse, K., Mondoukpè, T. and Edgard-Marius, O. (2021) Factors Associated with Pregnancy Outcomes in Hypertensive Pregnant Women in a District Hospital in Benin. Open Journal of Epidemiology, 11, 420-432.

https://doi.org/10.4236/ojepi.2021.114034

Received: September 2, 2021

Accepted: November 7, 2021

Published: November 10, 2021

Copyright $\odot 2021$ by author(s) and Scientific Research Publishing Inc. This work is licensed under the Creative Commons Attribution International License (CC BY 4.0).

http://creativecommons.org/licenses/by/4.0/

\begin{abstract}
Introduction: Hypertension is a major cause of maternal and perinatal morbidity and mortality. This study aims at exploring the outcomes of pregnancy and associated factors in hypertensive pregnant women in Comè district hospital from 2014 to 2016. Methods: This is a retrospective, analytical study carried out in June 2016, involving a total of 345 hypertensive patients. Socio-demographic and medical features, including pregnancy and foetal outcomes parameters, were recorded in the case files. Top-down stepwise logistic regression was performed at the $5 \%$ threshold. Results: The frequency of hypertensive disorders during pregnancy was estimated at $7.32 \%$ and unfavourable outcomes at $35.65 \%$. The adverse maternal outcomes recorded were postpartum death and haemorrhage whereas adverse foetal issues were prematurity, low birth weight, low Apgar scores, stillbirth and death. Factors statistically associated with pregnancy outcome were paucigravida $(\mathrm{OR}=2.01$ ([1.05 $3.88]), \mathrm{p}=0.035)$, history of stillbirth $(\mathrm{OR}=4.75([1.01-22.1]), \mathrm{p}=0.048)$ and anticonvulsant therapy $(\mathrm{OR}=0.32([0.19-0.54]), \mathrm{p}<0.001)$. Conclusion: Adequate monitoring via Antenatal Care (ANC) check-ups, timely recourse to care and an effective communication strategy should reduce hypertensive disorders incidence and adverse outcomes in pregnant women.
\end{abstract}

\section{Keywords}

Hypertensive Disorders, Pregnancy Outcome, Risk Factors, Benin

\section{Introduction}

Arterial Hypertension (AHT) is a public health problem around the world. Around 
$45 \%$ of deaths are attributable to heart disease and more than $50 \%$ to stroke [1], with AHT being the main risk factor. During pregnancy, the prevalence of AHT varies from $8 \%$ to $10 \%$ among pregnant women worldwide [2]. Hypertensive disorders of pregnancy are highly significant because they threaten the pregnancy in progress and often lead to multiple consequences for the mother and child. AHT causes complications in around $10 \%$ of all pregnancies around the world [2] and is responsible for $10 \%$ of maternal deaths during pregnancy [3]. According to the World Health Organization (WHO), the incidence of pre-eclampsia, one of the serious forms of the AHT in pregnancy, is seven times higher in developing countries ( $2.8 \%$ of live births) than in developed countries (estimated at $0.4 \%$ of live births) [4]. In West Africa, around $8 \%$ of the causes of maternal deaths are linked to hypertension disorders [5]. Perinatal mortality rates associated with hypertensive disorders range from 47 to 370 per 1000 births [6] [7]. Hypertensive disorders also increase the likelihood of death among newborns. One out of every four perinatal deaths is attributed to pre-eclampsia or eclampsia in low-income countries, and infants born from mothers with pre-eclampsia have a perinatal mortality rate three times higher in low-income countries than in high-income countries [1] [8]. Maternal complications due to hypertensive disorders include Retroplacental Haemorrhage (RPH), Postpartum Haemorrhage (PPH), intracranial haemorrhage and pulmonary oedema [7] [9] [10]. Hypertensive disorders can also trigger some severe forms of maternal complications, such as cardiovascular and cerebrovascular diseases, liver and kidney failure, placental abruption, Disseminated Intravascular Coagulation (DIC) and HELLP syndrome [11]. The factors most often associated with an unfavourable outcome of pregnancy in hypertensive pregnant women are socio-demographic and cultural factors, maternal and healthcare factors as shown in the conceptual framework below. The main factors are the age and level of education of the women, family and personal history, gestational age, parity, the severity of the AHT, pre-eclampsia, chronic hypertension, lack of prenatal monitoring and inadequate performance of the health system [7] [12] [13]. In Benin, various studies have been carried out on the risk factors for non-communicable diseases and have shown AHT to have a prevalence of $27.5 \%$ [14] [15]. The risk was higher among women of childbearing age, putting them at risk of hypertensive disorders before pregnancy. In 2010, a study showed that out of 5382 deliveries, 207 cases (equivalent to 37 per 1000 deliveries) involved eclampsia. Maternal and perinatal outcomes were unfavourable in $22.0 \%$ of cases [16]. In order to improve the quality of care and pregnancy outcomes in hypertensive pregnant women, the WHO recommends treatment and preventive treatment of pre-eclampsia and eclampsia [14]. Despite these provisions, pre-eclampsia continues to be a leading cause of maternal and perinatal mortality in sub-Saharan Africa [10]. In the Mono Department of Benin (located in the south-west of the country), particularly in the Comè-Bopa-Houéyogbé-Grand-Popo Health Zone (CBGH HZ), very few studies have taken into account the risk factors associated with pregnancy outcomes 
in pregnant women with high blood pressure, while routine data have highlighted cases of disorders related to pregnancy. Therefore, it is important to study the outcomes of pregnancy as well as related factors in hypertensive pregnant women in this district hospital with a view of improving maternal and perinatal healthcare quality.

\section{Framework and Methods}

\subsection{Study Framework}

This study was conducted in the district/health zone hospital of the ComèBopa-Grand-Popo-Houéyogbé (CBGH) in the Mono department, with a total population of 497,243 in the most recent general population and housing census [17]. The CBGH HZ is located in the south-east of Benin, about sixty kilometres from Cotonou, the most populous city and home to most of the country's largest institutions. Its economy is mainly based on informal sector activities. The main activities are: petty trading, crafts, agriculture, animal husbandry, fishing, sand and gravel quarrying. Women aged 15 to 49 during 2016 represented $22.33 \%$ of the total population of the HZ. The number of adults aged 15 and over with hypertension was 3773 , this equating to a prevalence of $20.13 \%$ with a case fatality of $7.7 \%$. The CBGH HZ hospital had the following departments: maternity, surgery, pharmacy, operating rooms, emergency care, paediatrics, ophthalmology, stomato-odontology, physiotherapy, and radiology. The maternity ward consisted of a gynaecologist, four midwives and four nursing assistants. Health data from this maternity department report a monthly average 138 women giving birth, of which 20 suffered from hypertension during pregnancy.

\subsection{Type of Study}

We carried out a cross-sectional, descriptive and analytical study in CBGH HZ hospital from 1 to 29 June 2017.

\subsection{Sample Population}

The sample population consisted of hypertensive pregnant women who gave birth in the CBGH health zone hospital from 1 January 2014 to 31 December 2016, represented by their health records. All women with incomplete files and multiple pregnancies were excluded. Thus, 345 health records meeting the inclusion criteria were retained out of the total 4708 records used for the study. In addition to these records, the gynaecologist and the five midwives from the maternity ward were interviewed using an interview guide.

\subsection{Study Variables}

The dependent variable is "outcome of pregnancy", which has two categories: unfavourable and favourable. It is unfavourable when the mother and/or newborn present with at least one of the following complications: postpartum haemorr- 
hage, abortion, premature delivery, and maternal death for the mother; Apgar score less than 7 , low birth weight, death in utero and perinatal death for the child. The outcome is favourable when both the mother and child do not present with any of these complications.

The independent variables are socio-demographic and cultural factors, maternal factors (parity, gravidity, BMI, family and obstetric history of hypertension, mode of delivery, diabetes, number of prenatal consultations (PNC), type of hypertension, severity of hypertension, acute foetal distress, HELLP syndrome, pregnancy complications) as well as healthcare factors (qualified personnel, staff training, availability of personnel, medicines and consumables, length of hospitalization, administered anticonvulsants (diazepam, magnesium sulphate), laboratory examination (albuminuria), nutritional advice, information on warning signs, treatment protocol and existence of a functional ambulance service). Statistical sufficiency was examined in order to minimize these biases. All variables were selected according to the scientific literature review and the guidelines of the Ministry of Health on pregnancy care [7] [9] [10] [12] [13] [14] [15] [16].

\subsection{Statistical Analysis}

Data were entered and analyzed using the program Stata 11. Qualitative variables were described by their frequency and quantitative variables by their mean with their standard deviation if the distribution is normal or by their median with their semi-interquartile range if the distribution is skewed. The analysis consisted in comparing proportions or means between the outcomes of pregnancy and the various independent variables by looking for associations between the dependent variable and independent ones through the Odds Ratios (OR) and their confidence interval to $95 \%$ (CI 95\%).

Using multivariate analysis, we used logistic regression to look for factors associated with pregnancy outcome. Variables with a significance level of less than $20 \%$ during bivariate analysis were added to the initial logistic regression model. We then proceeded with backward stepwise elimination of variables with a significance level greater than or equal to 0.05 and retaining those with a significance level less than $5 \%$ in the final model. The Hosmer-Lemeshow test was used to assess the goodness of fit of the final model. The model is suitable when the p-value is less than 0.05 .

\subsection{Ethical Considerations}

The research protocol was submitted for approval to the Ethics Committee of the Regional Institute of Public Health. The agreement of the management of the district hospital was then obtained before data collection was carried out, respecting the informed consent of respondents, anonymity and confidentiality of data. Codes were used for file processing and the health workers surveyed were free to choose whether or not to take part in the study. 


\section{Results}

\subsection{Description of the Sample Population}

As indicated above, the study population consisted of 345 pregnant hypertensive women out of a total of 4,708 cases processed over the data collection period from 1 January 2014 to 31 December 2016, representing 7.40\% of all cases. Figure 1 shows the distribution of hypertension cases in pregnant women from 2014 to 2016 . The monthly frequencies ranged from $5.5 \%$ to $11.9 \%$, with the highest observed in June (9.56\%) and September (11.9\%).

\subsection{Socio-Demographic and Cultural Characteristics}

The median age of the pregnant women was 25 years with an interquartile range of [20 - 30] years. The ages ranged from 15 to 46 years. 81.5\% of women were married and cohabiting with trade as their main occupation in $34.2 \%$ of cases. A history of caesarean section was most frequent $(8.1 \%)$, followed by a history of abortion (7.0\%) and hypertension in pregnancy (3.2\%). The median duration of hospitalisation of hypertensive women who gave birth in CBGH $\mathrm{HZ}$ was seven days with an interquartile range of [3 - 7] days.

\subsection{Adverse Pregnancy Outcomes}

The frequency of hypertension in CBGH HZ hospital was 7.3\% (345 out of 4,708 cases who delivered during the study period). Adverse maternal and perinatal outcomes accounted for $35.7 \%$ of all outcomes (123/345). Maternal outcomes were abortion $(0.3 \%), \mathrm{RPH}(0.3 \%)$ and maternal death (1.5\%). Perinatal outcomes were perinatal death (2.3\%), stillbirth (2.9\%) and low birth weight (16.5\%).

\subsection{Bivariate Analysis of Factors Related to the Pregnancy Outcomes in Hypertensive Pregnant Women in CBGH HZ Hospital from 2014-2016}

In the bivariate analysis, the type of hypertension was strongly associated with

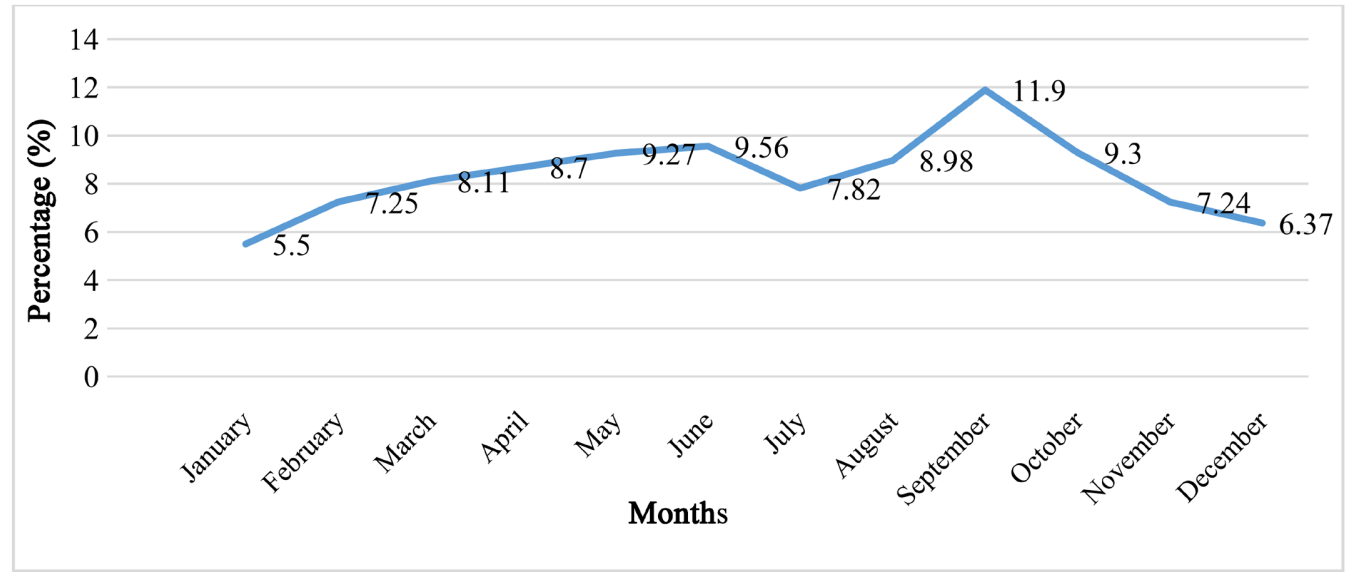

Figure 1. Monthly distribution of the proportion of hypertensive pregnant women in the maternity ward in Comè district hospital from 2014 to 2016. 
adverse pregnancy outcome. Woman with preeclampsia were approximately 1.8 times more likely to have an adverse pregnancy outcome than women with other forms of hypertension. On the other hand, women with severe hypertension were 1.6 times more likely to have an adverse outcome than those without hypertension.

Furthermore, it should be noted that the existence of albuminuria and anticonvulsant treatment were associated with the outcome of the pregnancy in contrast to the type of admission and the duration of hospitalization.

In short, three factors are related to pregnancy outcomes in hypertensive patients out of the twenty socio-demographic, cultural, maternal and the healthcare factors analyzed: hypertension, albuminuria and treatment with anticonvulsants. Table 1 presents a summary of the factors related to the pregnancy outcomes in hypertensive women.

\subsection{Multivariate Analysis of Factors Determining Pregnancy Outcomes in Hypertensive Women in CBGH HZ Hospital from 2014 to 2016}

The initial model retained the factors of family history of hypertension, the occupation of the pregnant women, parity, history of hypertension in pregnancy, history of stillbirth, the type of hypertension, the severity of the hypertension, albuminuria and anticonvulsant therapy, having a p-value of less than 0.20. In the final model, the three factors determining adverse pregnancy outcomes in hypertensive women, after adjustment, are: pregnancy, history of stillbirth, and anticonvulsant therapy. Paucigravid pregnant women with AHT are twice as likely to have an unfavourable outcome compared to multigravida women. Pregnant women with a history of stillbirth are 4.7 times more likely to have an unfavourable outcome following childbirth than those who do not. Pregnant women who have received anticonvulsant treatment are more likely to be at risk than those who have not. Table 2 presents the final model of factors determining pregnancy outcomes in hypertensive pregnant women.

\section{Discussion}

The objective of the present research was to study the pregnancy outcome and factors in hypertensive pregnant women who delivered at the maternity ward of the HZ CBGH hospital.

\subsection{AHT Importance in Pregnancy in CBGH HZ}

Hypertensive disorders during pregnancy remain a major public health problem and its incidence varies from country to country and from region to region. This study reveals an incidence of hypertensive disorders of $7.3 \%$. This result is close to the $7.9 \%$ incidence reported in a study carried out in India [18]. It is on the other hand lower than observed in Ghana (20.8\%) [19] and in Botswana (22.2\%) [12]. The differences observed could be explained either by the large number of hospitals involved in the other studies or by the method of diagnosing hypertension, 
Table 1. Link between the study factors and unfavourable outcomes of pregnancy in hyperten-sive pregnant women in the maternity ward of the Comè district hospital from 2014 to 2016.

\begin{tabular}{|c|c|c|c|c|c|c|}
\hline \multirow{2}{*}{ Explanatory variables } & \multirow{2}{*}{ Total (n) } & \multicolumn{2}{|c|}{ Unfavourable outcome } & \multirow{2}{*}{ ORb } & \multirow{2}{*}{ [CI95\% ORb] } & \multirow{2}{*}{$\mathrm{p}$-value } \\
\hline & & Yes & $\%$ & & & \\
\hline \multicolumn{7}{|l|}{ Marital status } \\
\hline Single & 64 & 20 & 31.25 & 1 & - & \\
\hline Married/cohabiting & 281 & 103 & 36.65 & 1.27 & {$[0.71-2.27]$} & 0.416 \\
\hline \multicolumn{7}{|l|}{ Gravida } \\
\hline Primigravida & 160 & 56 & 35.00 & 1.25 & {$[0.72-2.19]$} & 0.421 \\
\hline Paucigravida & 95 & 40 & 42.11 & 1.69 & {$[0.92-3.11]$} & 0.088 \\
\hline Multigravida & 90 & 27 & 30.00 & 1 & - & \\
\hline \multicolumn{7}{|l|}{ Parity } \\
\hline Nulliparous & 174 & 62 & 35.63 & 1 & - & \\
\hline Primiparous & 45 & 18 & 40.00 & 1.20 & {$[0.61-2.35]$} & 0.588 \\
\hline Pauciparous & 75 & 29 & 38.67 & 1.13 & [0.65 - 1.99] & 0.648 \\
\hline Multiparous & 51 & 14 & 27.45 & 0.68 & {$[0.34-1.36]$} & 0.279 \\
\hline \multicolumn{7}{|c|}{ History of AHT in pregnancy } \\
\hline No & 334 & 117 & 35.03 & 1 & - & \\
\hline Yes & 11 & 06 & 54.55 & 2.22 & {$[0.66-7.44]$} & 0.194 \\
\hline \multicolumn{7}{|l|}{ Family history of AHT } \\
\hline No & 340 & 119 & 35.00 & 1 & - & \\
\hline Yes & 05 & 04 & 80.00 & 7.42 & {$[0.82-60.21]$} & 0.074 \\
\hline \multicolumn{7}{|l|}{ History of abortion } \\
\hline No & 321 & 112 & 34.89 & 1 & - & \\
\hline Yes & 24 & 11 & 45.83 & 1.57 & {$[0.68-3.63]$} & 0.284 \\
\hline \multicolumn{7}{|l|}{ History of stillbirth } \\
\hline No & 337 & 118 & 35.01 & 1 & - & \\
\hline Yes & 08 & 05 & 62.50 & 3.09 & {$[0.72-13.17]$} & 0.127 \\
\hline \multicolumn{7}{|l|}{ History of caesarean section } \\
\hline No & 317 & 112 & 35.33 & 1 & - & \\
\hline Yes & 28 & 11 & 39.29 & 1.18 & {$[0.53-2.61]$} & 0.676 \\
\hline \multicolumn{7}{|l|}{ Diabetes } \\
\hline No & 341 & 122 & 35.78 & 1 & - & \\
\hline Yes & 04 & 01 & 25.00 & 0.59 & {$[0.06-5.81]$} & 0.658 \\
\hline \multicolumn{7}{|l|}{ Anaemia } \\
\hline No & 338 & 119 & 35.21 & 1 & - & \\
\hline
\end{tabular}




\section{Continued}

\begin{tabular}{|c|c|c|c|c|c|c|}
\hline Yes & 07 & 04 & 57.14 & 2.45 & {$[0.54-11.1]$} & 0.245 \\
\hline \multicolumn{7}{|l|}{ Type of AHT } \\
\hline Other AHT & 156 & 44 & 28.21 & 1 & - & \\
\hline Pre-eclampsia & 189 & 79 & 41.80 & 1.82 & {$[1.16-2.87]$} & 0.009 \\
\hline \multicolumn{7}{|l|}{ Severity of AHT } \\
\hline Not severe & 135 & 39 & 28.89 & 1 & - & \\
\hline Severe & 210 & 84 & 40.00 & 1.64 & {$[1.03-2.60]$} & 0.036 \\
\hline \multicolumn{7}{|c|}{ Acute foetal distress } \\
\hline No & 316 & 112 & 35.44 & 1 & - & \\
\hline Yes & 29 & 11 & 37.93 & 1.11 & {$[0.50-2.43]$} & 0.789 \\
\hline \multicolumn{7}{|c|}{ Retroplacental haemorrhage } \\
\hline No & 342 & 121 & 35.38 & 1 & - & \\
\hline Yes & 03 & 02 & 66.67 & 3.65 & {$[0.032-40.6]$} & 0.292 \\
\hline
\end{tabular}

Acute pulmonary oedema

$\begin{array}{lcccc}\text { No } & 343 & 121 & 35.28 & - \\ \text { Yes } & 02 & 02 & 100.0 & -\end{array}$

Type of admission

$\begin{array}{ccccccc}\text { Direct } & 87 & 32 & 36.78 & 1 & - & \\ \text { Referred } & 258 & 91 & 35.27 & 0.93 & {[0.56-1.55]} & 0.799\end{array}$

Duration of hospitalisation

$\begin{array}{lcccccc}\leq 7 \text { days } & 270 & 94 & 34.81 & 1 & - & \\ >7 \text { days } & 75 & 29 & 38.67 & 1.18 & {[0.69-2.00]} & 0.538\end{array}$

Existence of albuminuria

$\begin{array}{llllccc}\text { No } & 137 & 38 & 27.74 & 1 & - & \\ \text { Yes } & 208 & 85 & 40.87 & 1.80 & {[1.13-2.86]} & 0.013\end{array}$

Anticonvulsant therapy

Magnesium sulphate

Diazepam

Diazepam and magnesium sulphate

None

\begin{tabular}{cccccc}
100 & 50 & 50.00 & 1 & - & \\
50 & 23 & 46.00 & 0.85 & {$[0.43-1.68]$} & 0.644 \\
04 & 02 & 50.00 & 1 & {$[0.13-7.38]$} & 1.000 \\
191 & 48 & 25.13 & 0.33 & {$[0.20-0.55]$} & $<0.001$ \\
\hline
\end{tabular}

which was based on a single measurement of blood pressure during pregnancy.

The rise in hypertension during cold seasons has been reported by several authors who have shown that eclampsia is associated with cooler temperatures, periods with increased humidity or during precipitation [11] [20]. Lower temperature induced vasoconstriction could trigger hypertensive disorders. The study 
Table 2. Final model of factors determining pregnancy outcomes in hypertensive pregnant women in Comè district hospital from 2014 to 2016.

\begin{tabular}{cccc}
\hline Explanatory variables & ORb & [CI95\% ORb] & p-value \\
\hline Gravida & 1.37 & {$[0.75-2.52]$} & 0.301 \\
Primigravida & 2.01 & {$[1.05-3.88]$} & 0.035 \\
Paucigravida & 1 & & \\
Multigravida & & & \\
History of stillbirth & 1 & - & 0.048 \\
No & 4.75 & {$[1.01-22.1]$} & \\
Yes & & & \\
Anticonvulsant therapy & 1 & & - \\
Magnesium sulphate & 0.87 & {$[0.43-1.74]$} & 0.704 \\
Diazepam & 1.23 & {$[0.15-9.56]$} & 0.842 \\
None & 0.32 & {$[0.19-0.54]$} & $<0.001$ \\
\hline
\end{tabular}

showed an increase in the distribution of hypertension during the rainy seasons from May to September in southern Benin. The study showed that the median age of pregnant women was 25 years and the $20-24$ year old age group alone made up $30.4 \%$ of all cases. These results could be explained by the increased importance of reproduction for women in this age group. These results are similar to those in studies carried out in Ethiopia and Ghana [9] [19]. Nulliparas were also the most common (50.4\%). This result is also similar to another which reported 35.3\% [19], but contrary to another which reported that multiparas were more associated with pregnancy outcome [21]. In the study, caesarean was the main mode of delivery, with a very high rate of $66.7 \%$. This result is lower than the $90.8 \%$ reported in Nigeria [22], and higher than the $45.7 \%$ observed in Ghana [19]. On the other hand, it is similar to the $52.0 \%$ reported elsewhere [23], which shows that the indication of caesarean section in cases of hypertension in pregnancy is interpreted in varying ways, given the seriousness that this condition represents.

\subsection{Adverse Outcomes of Hypertension in Pregnancy in CBGH HZ}

The pregnancy outcome was unfavourable in $35.7 \%$ of cases and remains higher than that reported in the Netherlands, which was 17\% [13]. The difference in these results could be explained by several reasons: the CBGH $\mathrm{HZ}$ hospital has a midwife on call every 24 hours assisted by a nursing assistant; the only gynaecologist available was only present on working days, Monday to Friday; similarly, the operating room was shared by all surgical departments. These factors sometimes delayed the management of obstetric emergencies and affected the quality of care for pregnant women. It should also be noted that the majority of patients 
in our study had presented with severe hypertension (60.9\%), and more than half of them were pre-eclamptic (54.8\%). In the study, maternal death incidence was reported at $1.5 \%$ which is close to $1.7 \%$ maternal death found in Zimbabwe [24], but lower than the $2.8 \%$ reported in northern India [25]. The unfavourable perinatal outcomes were as follows: incidence of low birth weight was $16.52 \%$, low Apgar score in $14.8 \%$, prematurity in $16,6 \%$, stillbirth in $2.9 \%$ and early neonatal mortality in $2.32 \%$. Another study reported premature deliveries in $28.8 \%$ of cases, low birth weight in $56.30 \%$, stillbirths in $16.9 \%$ and perinatal death in $4.2 \%$ [25]. The differences in these results could be explained by the type of study carried out, where ours was prospective and therefore more reliable.

\subsection{Factors Associated with AHT Pregnancy Outcomes in CBGH HZ}

Paucigravid women were twice as likely to have an unfavourable outcome as multigravida women. In a study carried out in Lagune Mother and Child Hospital in Cotonou, Benin, the authors found a similar result of 1.5 [0.25 - 8.72] [26]. In contrast, it found that multiparity was among the key associated factors [27]. Pregnant women with a history of stillbirth in previous pregnancies were 4.8 times more likely to have an unfavourable outcome than those who did not. In the literature, this link between a history of stillbirth and pregnancy outcome has not been identified. This study did not show an association between albuminuria, severity of hypertension, length of hospital stay and pregnancy outcome. These results are contrary to those found by another study [9], which found that presence of albumin in the urine, severity of hypertension and duration of hospitalisation of more than seven days, increased the risk of an unfavourable maternal outcome. Hypertensive patients who had not received anticonvulsant therapy were more likely to have a favourable outcome than those who received treatment with magnesium sulphate, which is contrary to the data reported in the literature. Indeed, several studies have shown the effectiveness of magnesium sulphate in the prevention and treatment of seizures in eclampsia compared to diazepam and phenytoin. Women who received magnesium sulphate were less likely to have an unfavourable outcome [26]. This difference with the study can be explained by the fact that pregnant women who did not receive anticonvulsant therapy were treated immediately and in the majority of cases had a caesarean section; which allowed unfavourable outcomes to be significantly reduced. It should also be noted that magnesium sulphate is often out of stock in the CBGH HZ hospital, with the families of the patients sometimes forced to go to get them from pharmacies in the large southern cities of Benin (Cotonou and Porto-Novo). This could delay the administration of these medicines and accelerate the recourse to caesarean section for these pregnant women, who would run a greater risk of an unfavourable outcome. In terms of policy, it is important to pay more attention to pregnant women with hypertension, particularly in the rainy season as some studies have recommended [1] [28]. Likewise, a communication campaign aimed 
at those at lower risk is necessary to prevent hypertension as well as the resurgence of non-communicable diseases in Benin.

\section{Conclusion}

Hypertensive disorders during pregnancy continue to be a fairly common complication leading to morbidity and mortality among mothers and newborns in CBGH HZ in Benin. The adverse maternal outcomes noted were death and postpartum haemorrhage; and unfavourable newborn outcomes were low birth weight, prematurity, low Apgar score, stillbirth and perinatal death. The study showed that the factors associated with these unfavourable outcomes were paucigravid women with a history of stillbirth and those who received anticonvulsant therapy. Stakeholders involved in the management of obstetric emergencies should pay more attention to hypertension in pregnancy by strictly following recommendations, particularly those of the WHO. A large-scale prospective study would be necessary to obtain a deeper understanding of all the aspects of this public health problem and reduce adverse outcomes.

\section{Limitations of the Study}

The main limitation of the study is the information bias known in the literature related to the completeness of recorded information in the medical records. To minimize these biases, a cross-referencing of data from different existing data carriers was done.

\section{Acknowledgements}

We are thankful to all the Comè District Hospital for cooperation and facilitation of the data collection.

\section{Conflicts of Interest}

The authors declare no conflicts of interest regarding the publication of this paper.

\section{References}

[1] World Health Organization (WHO) (2013) A Global Brief on Hypertension: Silent Killer, Global Public Health Crisis: World Health Day 2013. https://www.who.int/publications/i/item/a-global-brief-on-hypertension-silent-kille r-global-public-health-crisis-world-health-day-2013

[2] Duley, L. (2009) The Global Impact of Pre-Eclampsia and Eclampsia. Seminars in Perinatology, 33, 130-137. https://doi.org/10.1053/j.semperi.2009.02.010

[3] Sjaus, A., McKeen, D.M. and George, R.B. (2014) Hypertensive Disorders of Pregnancy. Canadian Journal of Anaesthesia, 63, 1075-1097. https://doi.org/10.1007/s12630-016-0689-8

[4] Naeem, M.A., Naeem, M.U. and Hanif, A. (2017) Pregnancy Outcomes: A Comparative Study of Hypertensive and Normotensive Pakistani Population. The Professional Medical Journal, 21, 347-353. 
https://doi.org/10.29309/TPMJ/2014.21.02.2067

[5] Ngoc, N.T., Merialdi, M., Abdel-Aleem, H., Carroli, G., Purwar, M., Zavaleta, N., Campódonico, L., Ali, M.M., Hofmeyr, G.J., Mathai, M., Lincetto, O. and Villar, J. (2006) Causes of Stillbirths and Early Neonatal Deaths: Data from 7993 Pregnancies in Six Developing Countries. Bulletin of the World Health Organization, 84, 699-705. https://doi.org/10.2471/BLT.05.027300

[6] Browne, J.L., Vissers, K.M., Antwi, E., Srofenyoh, E.K., Van der Linden, E.L., Agyepong, I.A., Grobbee, D.E. and Klipstein-Grobusch, K. (2015) Perinatal Outcomes after Hypertensive Disorders in Pregnancy in a Low Resource Setting. Tropical Medicine \& International Health, 20, 1778-1786. https://doi.org/10.1111/tmi.12606

[7] Redman, C.W. (2011) Hypertension in Pregnancy: The NICE Guidelines. Heart, 97, 1967-1969. https://doi.org/10.1136/heartjnl-2011-300949

[8] Jasovic-Siveska, E., Jasovic, V. and Stoilova, S. (2011) Previous Pregnancy History, Parity, Maternal Age and Risk of Pregnancy Induced Hypertension. Bratislavske Lekarske Listy, 112, 188-191. https://pubmed.ncbi.nlm.nih.gov/21585125/

[9] Seyom, E., Abera, M., Tesfaye, M. and Fentahun, N. (2015) Maternal and Fetal Outcome of Pregnancy Related Hypertension in Mettu Karl Referral Hospital, Ethiopia. Journal of Ovarian Research, 8, Article No. 10. https://doi.org/10.1186/s13048-015-0135-5

[10] Umesawa, M. and Kobashi, G. (2017) Epidemiology of Hypertensive Disorders in Pregnancy: Prevalence, Risk Factors, Predictors and Prognosis. Hypertension Research, 40, 213-220. https://doi.org/10.1038/hr.2016.126

[11] Abalos, R., Ellasus, R. and Gutierrez, J.M. (2015) Fetomaternal Outcomes of Hospitalized Hypertensive Gravida in Shaqra General Hospital: A Retrospective Study. International Journal of Advanced Nursing Studies, 4, Article ID: 3827. https://doi.org/10.14419/ijans.v4i1.3827

[12] Johnson, K.M., Zash, R., Haviland, M.J., Hacker, M.R., Luckett, R., Diseko, M., Mayondi, G. and Shapiro, R. (2016) Hypertensive Disease in Pregnancy in Botswana: Prevalence and Impact on Perinatal Outcomes. Pregnancy Hypertension, 6, 418-422. https://doi.org/10.1016/j.preghy.2016.10.002

[13] Broekhuijsen, K., Ravelli, A.C.J., Langenveld, J., van Pampus, M.G., van den Berg, P.P., Mol, B.W.J., et al. (2015) Maternal and Neonatal Outcomes of Pregnancy in Women with Chronic Hypertension: A Retrospective Analysis of a National Register. Acta Obstetricia et Gynecologica Scandinavica, 94, 1337-1345.

https://doi.org/10.1111/aogs.12757

[14] World Health Organization (WHO) (2011) Recommendations for Prevention and Treatment of Pre-Eclampsia and Eclampsia.

http://whqlibdoc.who.int/publications/2011/9789241548335 eng.pdf

[15] World Health Organization (WHO) Benin: Non-Communicable Diseases and Conditions.

[16] Ministry of Health of Benin (2016) Restitution of the Survey on Non-Communicable Diseases in Benin: Alarming Results for Raising Awareness among the Population and Health Authorities.

http://reliefweb.int/sites/reliefweb.int/files/resources/com\%20presse $\% 20$ conjoint $\% 2$ 0Restitution\%20MNT20072016\%20R\%C3\%A9v\%20FA\%2019h30.pdf

[17] INSAE (2016) Population Size of Villages and City Districts in Benin (RGPH-4, 2013). 85 p.

https://insae.bj/images/docs/insae-statistiques/demographiques/population/Effectifs \%20de\%20la\%20population $\% 20$ des $\% 20$ villages $\% 20$ et $\% 20$ quartiers $\% 20$ de $\% 20$ ville $\%$ 
20du\%20benin/Cahier\%20Village\%20RGPH4\%202013.pdf

[18] Kolluru, V., Harika, R. and Kaul, R. (2016) Maternal and Perinatal Outcome Associated with Pregnancy Induced Hypertension. International Journal of Reproduction, Contraception, Obstetrics and Gynecology, 5, 3367-3371. https://doi.org/10.18203/2320-1770.ijrcog20163113

[19] Adu-Bonsaffoh, K., Obed, S.A. and Seffah, J.D. (2014) Maternal Outcomes of Hypertensive Disorders in Pregnancy at Korle Bu Teaching Hospital, Ghana. International Journal of Gynaecology \& Obstetrics, 127, 238-242. https://doi.org/10.1016/j.ijgo.2014.06.010

[20] Berhan, Y. and Endeshaw, G. (2015). Maternal Mortality Predictors in Women with Hypertensive Disorders of Pregnancy: A Retrospective Cohort Study. Ethiopian Journal of Health Sciences, 25, 89-98. https://doi.org/10.4314/ejhs.v25i1.12

[21] Endeshaw, G. and Berhan, Y. (2015) Perinatal Outcome in Women with Hypertensive Disorders of Pregnancy: A Retrospective Cohort Study. International Scholarly Research Notices, 2015, Article ID: 208043. https://doi.org/10.1155/2015/208043

[22] Olusanya, B.O. and Solanke, O.A. (2012) Perinatal Outcomes Associated with Maternal Hypertensive Disorders of Pregnancy in a Developing Country. Hypertension in Pregnancy, 31, 120-130. https://doi.org/10.3109/10641955.2010.525280

[23] Hossain, N., Shah, N., Khan, N., Lata, S. and Khan, N.H. (2015) Maternal and Perinatal Outcome of Hypertensive Disorders of Pregnancy at a Tertiary Care Hospital. Journal of the Dow University of Health Sciences, 5, 12-16.

[24] Ngwenya, S. (2017) Severe Preeclampsia and Eclampsia: Incidence, Complications, and Perinatal Outcomes at a Low-Resource Setting, Mpilo Central Hospital, Bulawayo, Zimbabwe. International Journal of Women's Health, 9, 353-357. https://doi.org/10.2147/IJWH.S131934

[25] Sachan, R., Patel, M. L., Sachan, P., Gaurav, A., Singh, M. and Bansal, B. (2013) Outcomes in Hypertensive Disorders of Pregnancy in the North Indian Population. International Journal of Women's Health, 5, 101-108. https://doi.org/10.2147/IJWH.S40473

[26] Saizonou, J., Agueh, V., Ouendo, E.M., Belemou, B., Makoutode, M. and Bazira, L. (2010) Issues maternelles, périnatales et ses facteurs associés à l'éclampsie à l'hôpital de la Mère Enfant Lagune de Cotonou au Bénin. Médecine d Afrique Noire, 57, 563-570.

http://www.santetropicale.com/sites pays/resume oa.asp?id article $=2001$ \&revue $=$ man\&rep=benin

[27] Ganzevoort, W., Rep, A., de Vries, J.I., Bonsel, G.J., Wolf, H. and PETRA-Investigators (2006) Prediction of Maternal Complications and Adverse Infant Outcome at Admission for Temporizing Management of Early-Onset Severe Hypertensive Disorders of Pregnancy. American Journal of Obstetrics and Gynecology, 195, 495-503. https://doi.org/10.1016/j.ajog.2006.02.012

[28] Morikawa, M., Yamada, T., Yamada, T., Cho, K., Sato, S. and Minakami, H. (2014) Seasonal Variation in the Prevalence of Pregnancy-Induced Hypertension in Japanese Women. Journal of Obstetrics and Gynaecology Research, 40, 926-931. https://doi.org/10.1111/jog.12304 